\title{
El último Guillén. Hacia una segunda edición de Final
}

ANTONIO GÓMEZ YEBRA

Universidad de Málaga

Cuando la primera edición de Final llegó a manos del poeta en los primeros días de 1982, su autor desconocía el tiempo que le quedaba de vida, y rogaba al cielo un par de años más para poder subsanar erratas y completar el volumen, menor, en extensión, que el resto de los tomos de Aire Nuestro.

Tal y como había hecho con Cántico-28, decidió reconstruir algunos poemas, suprimir o añadir otros, y cambiar de lugar varios de los aparecidos en la primera edición.

Pero los acontecimientos, los homenajes, la enfermedad y su muerte subsiguiente, obstaculizaron hasta cierto punto la realización de sus deseos. Y digo «hasta cierto punto» porque J. Guillén había ido anotando en un ejemplar de Final la mayor parte de las modificaciones que tenía intención de incorporar al texto primero.

Esta labor correctora de índole artesanal ${ }^{1}$ la fue efectuando también sobre los ejemplares que regalaba a sus amigos, por lo que será

1 Véase sobre este tema mi artículo «La artesanía poética de J. Guillén», en J.G., Algunos poemas, publicaciones de la Librería Anticuaria del Guadalhorce, Málaga, 1981, [s.p.] 
frecuente en un futuro próximo la aparición de textos en los cuales su fina caligrafía haya hecho anotaciones diversas.

Localizar todos los ejemplares para efectuar una comparación de poemas con el fin de estudiar posibles variantes no deja de ser una misión atractiva, pero no es ésa la meta que me he trazado para este artículo. Mi trabajo pretende dar a conocer las variantes que pueden aparecer en la 2. ${ }^{a}$ edición de Final, actualmente en vías de preparación.

Por gentileza del poeta, de su hijo y de A. Piedra, cuento, a la hora de iniciar este estudio, con una fotocopia del ejemplar de Final donde el poeta anotó un buen número de variantes, con mi propio ejemplar corregido por su autor, con algunos poemas nuevos editados en diversos medios de comunicación, y con manuscritos de la mayoría de los poemas nuevos.

\section{Presentación de textos nuevos}

A sabiendas de que mi presentación de textos puede no coincidir con la definitiva, por los motivos que se verán, me limitaré a ordenar los poemas en dos grupos: a) aquellos cuya situación en Final quedó fijada por la voluntad del poeta; b) el resto de los poemas, editados ocasionalmente o no.

Dentro del primer grupo cabe incorporar las adiciones, las variaciones y aún las supresiones a que hubiera lugar siguiendo el deseo del poeta.

\section{Adiciones a la primera edición}

En el ejemplar de Final que el poeta modificó de puño y letra se observan, página a página, las siguientes adiciones: P. 51: Se varía la numeración del subpoema ${ }^{2} \mathrm{n} .^{\circ} 5$ de Más noches para convertirlo en el subpoema 6 , y así dar cabida a un nuevo texto que ocuparía el $n .^{\circ} 5$ :

2 Denomino subpoema a aquellos conjuntos de versos (estrofas, epigramas) que el autor ordena correlativamente con números árabes, pero sin título, aparecidos dentro de apartados de considerable extensión. 
La alta noche transcurre a pasos lentos

entreverados por lento monólogo.

¿Hacia un mundo la nada estallaría,

hace millones, infinitos años?

Yo siento las estrellas invisibles

limpias de azar - ¿y Dios? - limpias de caos.

En busca de armonía yo me inserto,

mínimo ser incluido en el cosmos.

¿Y yo qué soy con mis tercas palabras?

Este texto presenta un paralelismo evidente con el $\mathrm{n} .^{\circ} 1$ de Dentro del mundo (p. 13) y el poema Astronomía (p. 104). P. 94: La anotación manuscrita aporta al subpoema 5 de ¿Quién seré? un único verso: «La gran frase de Ortega recordemos»).

Ignoro si se trata de concluir dicho subpoema con esa apostilla o si el poeta deseaba que se añadiese el resto del conjunto poético que ahora propongo:

La gran frase de Ortega recordemos.

Yo soy yo - ¿quién, yo? - y mi circunstancia.

Mi circunstancia con diversa fuerza...

Se nos impone a veces enemiga:

Dictadura - con nuestras artimañas

de resistencia o viaje. Normalmente

la circunstancia ¿no es el aire nuestro?

Realidad que nutre y se respira, amistad, el amor, la intensa Historia, que se llama, feliz, el gran Ortega. ${ }^{3}$

Espero que en la edición definitiva se incluya el texto completo y no solamente el primer verso.

P. 111: Para ser incluido en esta página, el autor anotó en la 120 el poema Con esperanza:

Crimen. Terror de masas. Humos, vahos.

Quiere imponerse un misterioso reto.

La barbarie es quien busca siempre el caos

de un poder absoluto al fin completo.

¿Otra vez? No.

Queremos, sí, cultura y libertad y convivencia

mientras tanto el supremo Viva el Rey,

la contradictadura.

Paz. ¿La destrucción de este planeta?

3 Este texto fue publicado bajo el título La gran frase, en Homenaje a Salvador Rueda, Corona del Sur, n. ${ }^{\circ}$ 37-38, Málaga, 1983, [s.p.] y en Ya, 8-2-84, p.35. 
¿Somos cuerdos o somos tontilocos?

La vida es vida si es con esperanza.

El hombre tiene en mano su destino.

Este poema se ha formado sobre dos epigramas de la página 171. El primero de ellos, que ocupaba el lugar $\mathrm{C}^{4}$ en dicha página, supone los cuatro primeros versos, mientras que el segundo, incluido en la $\mathrm{Fe}$ de erratas, ha sufrido una modificación para incorporarse a los versos 6,7 y $8:$

Cultura y libertad y convivencia.

Mientras tanto el supremo Viva el Rey la contradictadura.

El resto del poema presenta puntos de contacto con el epigrama A de p. 174, y con ¿Fin del mundo? (pp. 328-329).

P. 135: Se añade el subpoema 21:

Un galardón caído de los cielos, esos tan generosos con el hombre, sorprendido, feliz, ruborizado...

¿No será peligrosa tanta suerte?

El poeta se yergue agradeciendo

la grata coyuntura de la Historia.

Ya sonarán fatales confusiones.

Es indudable que todo el poema remite al subpoema 18 de Vida de la expresión (p. 81), que ahora se anota:

Cae del cielo un premio literario como azar de favor innecesario tal generosidad con el artista no es ninguna ilusión, está a la vista - ¿Yo el escogido? Juvenil sorpresa. ¿La vida es un zigzag más que una empresa?

La diferencia entre ambos poemas es que mientras en este caso se presenta una alegría transparente, en el nuevo subpoema existe una bien fundamentada actitud de recelo por parte del poeta.

P. 137: Al subpoema 22 (ahora 23, si tenemos en cuenta lo recién expresado) se añade lo siguiente:

A su nivel más tosco

4 Las letras mayúsculas con las que indico la situación de algún epigrama no existen en Final, pero ayudan a localizar los poemas en cada página. 
este país es una trinidad:

un ejército, clero y las políticas.

¿Y todo en decadencia se resuelve,

y quizá destrucción, civil la lucha?

Al margen, por de pronto, los mejores.

Estos seis versos proceden del apartado I del Epílogo con exclusión de los versos que vimos para ser incluidos en p. 111 .

P. 143: Al poema En suma se añaden los versos que ocupaban la p. 348 .

P. 171: Suprimido el epigrama C, Terror de masas. Humos, vahos, se da paso al siguiente:

Ya la señora estaba agonizando,

su confesor la ayuda a bien morir.

-Debe de estar muy tranquila.

Nuestro Señor con los brazos abiertos

la acogerá en su gloria.

¿Temores? No hay motivo.

Por fin,

dijo la vocecilla moribunda.

-Sí, sí, pero como en casa... en ninguna parte.

¡En casa! En este planeta. ${ }^{5}$

Este poema supone un magnífico complemento a la idea guilleniana del destino terrenal del hombre, que se apunta, entre otros lugares de Final, en el subpoema 4 de Dentro del mundo: «Yo, terrenal.// De acuerdo» (p. 15).

\title{
P. 172: Se incluirá un nuevo epigrama:
}

\author{
Anteriores analfabetos \\ a la antigua Roma latina \\ asesinan con ciega inquina: \\ son ya los bárbaros completos ${ }^{6}$.
}

5 Este poema se publicó en Homenaje a J. Guillén, voz acorde, Fundación Municipal de Cultura, Ayuntamiento de Valladolid, 1982, p. 339, y posteriormente en J.G., Poemas malagueños, Excma. Diputación de Málaga, Málaga, 1983, p. 107.

6 Epigrama publicado con el que comienza «No pasan los camellos» y con el que lo hace «La vida bien vivida y entendida», en Maestros de la poesía contemporánea, Librería Papiro, Cádiz. Con un aguafuerte de Hernán. Sin fecha, aunque apareció en febrero de 1983. Los acompañaban estas palabras de Gillén: «Estos epigramas pertecerán a la 2. a edición posible de Final, en la serie Epigramas. La primera edición está llena de erratas. el poeta debe aguardar pacientemente esta reimpresión corregida y aumentada. J. G.». 
P. 184: Bajo el vocablo (ADIVINANZA) (Sic), el poeta ha añadido: «¿De qué países?, sin duda para que no se supusiera que lo siguientes epigramas podían aplicarse a una sola región del mundo. Conversando con el poeta me confesó que se refería fundamentalmente a los países sudamericanos.

P. 194: Añade el siguiente epigrama:

No pasan los camellos

por esos ojos críticos de aguja...

ni las obras maestras.

Que tanta historia se derrumbe y cruja exquisito menor. ${ }^{7}$

P. 201: Modificada la numeración de los subpoemas de esta página, se introduce, con el número 2 , el siguiente:
Nos sonroja nuestra Historia:
La época del secuestro.
Esa confusión de ideas
alcanza un grado siniestro.
Los criminales se creen
inspirados por el estro
de la gran Revolución:
El sumo derecho nuestro.
Monstruo al fin el asesino,
que ya es fantasma de espectro. ${ }^{8}$

Este texto parece muy próximo al recién anotado, Anteriores analfabetos, por lo que da la impresión de señalar hacia momentos concretos de los ochenta en que la inseguridad ciudadana parecía ser el tributo de la democracia.

P. 333: Tras el poema Cuando contemplo el cielo se añade Inspiraciones:
Culminación de arranque, peripecia, si tuviese fortuna alguna vez, suene mi voz serenamente recia, nada falaz, tal vez más bien feliz si una Musa guiase paso a paso la inspiración en rítmico desliz. Con alegría yo conduzca el verso

7 Véase la nota anterior.

¿ Este poema, manuscrito, fue publicado en la Revista de Feria del Excmo. Ayuntamiento de Fernán-Núñez, Córdoba, 1982, [s.p.]. 
que fatalmente impulse hacia la luz

siempre en contacto con el universo. ${ }^{9}$

P. 335: Después del poema Otra fe también, se ha añadido el titulado En último término:

Mi labor, mi ambición son en resumen:

Identidad personal en conjunto

coherente de obra: poesía.

Un honesto servicio de cultura

al sensible lector, ardua sentencia. ${ }^{10}$

Este poema es un magnífico complemento para la sección En tiempo fechado, a la que se va a incorporar, aunque acaso fuera conveniente situarlo precediendo a Otra fe también, con el fin de mantener el sentido de redondez del apartado, que empieza con el tema de la salida del sol y termina con la muerte.

\section{Variaciones a la primera edición ${ }^{11}$}

P. 51: Como ya advertí, el subpoema 5 pasa a ser el 6, a fin de dar entrada a un texto nuevo. En este subpoema 5 se eliminan la línea blanca que separaba los versos 9-10, y el sangrado del 11, probablemente para disponer de más espacio en la página.

P. 64: El subpoema 18 de La Expresión se modifica en su verso 4:

$F \quad$ : La más intensa conducta y basta: y artesano.

$F(2)$ : La más intensa conducta y basta: soy artesano. ${ }^{12}$

Tengo motivos para pensar que el poeta se olvidó de tachar la sílaba «in» de la tercera palabra, por lo que el verso es pentadecasílabo, mientras los tres anteriores del subpoema son alejandrinos.

P. 75: El subpoema 2 de Vida de la expresión presenta esta modificación:

9 Del mismo modo que el anterior, este poema, manuscrito, se editó en la Revista de Feria del Excmo. Ayuntamiento de Fernán-Núñez, Córdoba, 1983, [s.p.]

10) Poema publicado en Poesía, RIIP, Ministerio de Cultura, M., 1983, p. 30.

$\because$ Solamente tendré en cuenta las variantes, nunca las correcciones de erratas, a no ser que presenten características especiales.

12 Como hice en nota 4 , utilizo la sigla $F$ para referirme a la primera edición de Final, y $F(2)$ para la segunda, aún por publicar. 
$F$ : Placer en relación que va creándose.

$F(2)$ : Placer con relación que va creándose.

Tal vez el cambio de preposiciones se deba a motivos de eufonía, ya que en $F$ existían tres vocales e en tres sílabas sucesivas.

En esta misma página se sustituye el punto final del verso 2 (subpoema 3) por una coma.

P. 77: El subpoema 7 se modifica en su segundo verso:

$F \quad:$ El alpinista cuenta.

$F(2)$ : En el alpinista cuenta.

Sin modificar el sentido se ha conseguido un nuevo octosílabo en un poema en que disonaba el único heptasílabo entre octosílabos.

P. 82: El verso 19 del subpoema 19 se verá alterado:

$F \quad:$ De unos seres triunfantes.

$F(2)$ : De unos seres olímpicos.

Es una vuelta atrás, al texto originario, que el poeta me cedió en marzo de 1981.

P. 84: El subpoema 22 también se verá modificado:

$F$ : Estupendo poeta ilimitado.

$F(2)$ : El sublime poeta ilimitado.

Es, también, una recuperación del texto primitivo.

P. 86: El subpoema 25 presentará las siguientes transformaciones:

$F$ : Artesano - palabra digna, pulcra-

$F(2)$ : Artesano - palabra digna y bella-

Supone volver al primer texto.

V. 14: Aparecerá línea blanca que lo separa del $15^{13}$.

V. $17, F$ : O quizá por capricho, nubarrones.

$F(2)$ : O quizá por capricho, entre unas nubes.

Con la variante se ha conseguido eliminar el matiz negativo que parecía acompañar a la primera versión sin modificar fundamentalmente el verso.

13 En su publicación primera este poema contaba solamente con los primeros catorce versos. 


\section{V. $18, F$ : Esta irrupción centella \\ $F(2)$ : Esta irrupción de gracia.}

Puesto que en todo el poema se aborda el tema de la inspiración, resulta más propia la segunda versión que la primera.

V. $19, F$ : No es cita inesperada.

$F(2)$ : No es cita de aventura.

Varía el sentido temporal del poema desde un matiz de pasado a uno de futuro.

\section{V. $21, F$ : Tal musa, muy solícita \\ $F(2)$ : Tal musa, ya solícita.}

Con el cambio se consigue dotar de temporalidad al verso y además eliminar un adverbio muy, bastante repetido en la obra.

P. 135: Se elimina el sangrado en el verso 5 del subpoema 19, sin duda para ganar espacio, necesario si se pretende introducir un poema nuevo en la misma página.

P. 137: Aparte del cambio de numeración producido por la introducción de un subpoema nuevo en p. 135, se elimina la línea blanca del verso 10 y se añade parte del Epílogo, como ya se vio más arriba.

P. 152: El subpoema 9 de Fuerza bruta sufrirá esta modificación:

V. $6, F$ : Recubren el país con dolor y crimen.

$F(2)$ : Recubren el país con dolo y crimen.

Es una corrección de errata que no se había advertido en Fe de erratas, y que suponía la aparición de un dodecasílabo donde debiera haber un endecasílabo.

P. 201: En el subpoema 1 de Tiempo de espera se elimina el sangrado del verso 2 . Este mismo subpoema se une con el 2 y se da entrada a un nuevo subpoema 2 del que ya he hablado más arriba.

P. 306: El apartado III de Blancanieves presentará una variante:

V. $11, F$ : No será ajeno a la Historia. $F(2)$ : No será ajeno a Historia.

No es de extrañar la supresión del artículo, con la consiguiente pérdida de una sílaba, puesto que el poema está construido en heptasílabos y endecasílabos.

P. 312: El poema Alfonso Canales presentará estas variantes: 
V. 9: $F$ : Acedía en la raíz involuntaria.

$F(2)$ : Acedia en la raíz involuntaria.

Es una corrección de errata que suponía un verso sin sentido.

V. 23, $F$ : De todos los muertos. iResurrectos!

$F(2)$ : $Y$ de todos los muertos. ¡Resurrectos!

Se hacia necesaria una sílaba más, que ya aparecía en el texto ori، ginal, para que el verso fuese endecasílabo.

P. 333: Se eliminarán las líneas blancas del poema Cuando contemplo el cielo. De esta manera se dará mayor espacio al poema que se incorporará a esa página: Inspiraciones.

P. 345: Se subdividirá el subpoema 7 en 7 y 8 , con lo que ganará en sentido. Aquí se incorporará también el subpoema 9, procedente del Epílogo II ${ }^{14}$.

\title{
Supresiones
}

Las supresiones de textos aparecidos en la primera edición son escasas. Solamente desaparece el epigrama B de p. 194, indicado ya en la $\mathrm{Fe}$ de erratas, y se cambia de lugar el $\mathrm{C}$ de p. 171, sin suprimirlo.

\section{Otros poemas}

Dentro del grupo de poemas escritos con posterioridad a la primera edición de Final pueden hacerse dos apartados: a/ poemas editados ocasionalmente; $\mathrm{b} /$ poemas inéditos. A/ Poemas editados ocasionalmente

\author{
PESADILLA \\ Hubo de pronto algo salvaje un día. \\ ¿En la Historia de España? ¿ Qué ha ocurrido? \\ Violencia brutal y su fracaso. \\ Hubo después aclaraciones torpes \\ que intentan ser jurídicas. Bochorno.
}

14 Ya ha sido publicado en Poesía, RIIP, n. ${ }^{\circ} 7$, mayo de 1983, p. 44, con una estructura en la que separó los versos dos a dos, para dejar el último escalonado. 
Los procesados logran demostrarnos su condición vulgar irremediable.

Hay, por fin, más bochorno, más fracaso.

¿O será esto un sueño pesadísimo?

¿Qué pesadez total de pesadilla! ${ }^{15}$

Este poema parece hacer referencia al intento de golpe de Estado de 23 de febrero de 1981, lo que se confirma consultando los títulos que han de seguir a éste: Lo peorcito, Golpe, y La peor tradición. Se trata de un conjunto nuevo sobre un mismo tema de actualidad político-social a la que el poeta sumó su voz de protesta e indignación.

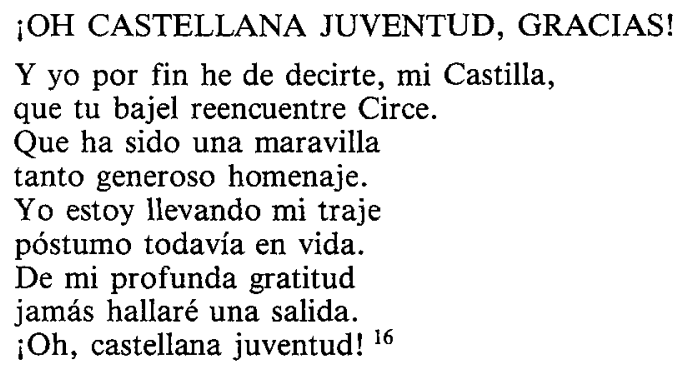

Es un poema escrito por J. Guillén para agradecer el homenaje que le ofreció su ciudad natal en noviembre de 1982. Con toda probabilidad no será incluido en la segunda edición de Final, pasando así a engrosar el número de poemas que su autor no ha querido introducir en Aire Nuestro por diversas causas.

\section{NUESTRA FE}

La tentativa heroica de dar sentido al mundo, al hombre y a la vida, por fin a nuestra muerte. ${ }^{17}$

15 Editado en Carpa, n. ${ }^{\circ} 100$, junio de 1982, p. 8, y posteriormente bajo forma de pliego, en tirada de 100 ejemplares, el día 18 de enero de 1983, por S. López Becerra, del que hablaré en nota 31 . Tuve también ocasión de incluirlo en J. G., Poemas malagueños ya citado, p. 105.

16 Esta décima que Guillén leyó telefónicamente a través de una emisora de radio de Valladolid, fue publicada en El Norte de Castilla de la misma localidad, el 14 de noviembre de 1982 , p. 40.

17 Texto publicado en un catálogo-invitación del malagueño Colectivo Palmo, en diciembre de 1982, cuando dedicó un homenaje pictórico al poeta. Su propio autor me lo proporcionó manuscrito para ser editado en J. G., Poemas malagueños, ya citado, p. 106. 
No sería descabellado introducir este pequeño texto en p. 335, antecediendo al que lleva por título Otra fe también aunque temo que no será incorporado a la $2{ }^{a}$ edición.

\section{NOVENTA}

\section{I}

18 de enero de 1983

Tengo tan buena suerte que soy nonagenario. No sé si algún poeta que hablase nuestro idioma subió por el Parnaso a tan dichosa loma.

El ritmo guía y a veces por un mundo muy vario. ${ }^{18}$

II

Sí, cumplí mis noventa

de modo natural.

La vida cotidiana

va por su curso al mar.

III

Cesaron las alharacas.

Sin inquietud de monólogos

voy sereno al desenlace

$\tan$ callando.

Puede asegurarse que los tres apartados pertenecen a otros tantos momentos sucesivos; el primero cuando se están realizando los homenajes de Valladolid y Málaga, el segundo acaso en los días próximos siguientes a tales acontecimientos (19 ó 20 de enero de 1983), y el tercero a finales de enero del mismo año ${ }^{19}$.

\section{TU CUMPLEAÑOS}

$$
9 \text { de febrero }
$$

$$
\text { iVida }
$$

Tan cotidiana! Sin disculpa

«A la altura de las circunstancias», p. 525

Es hoy tu cumpleaños,

que tu apariencia no denuncia.

18 Este serventesio en alejandrinos se publicó en SUR, Málaga, el 16 de enero de 1983, lo cual indica que el poeta lo había compuesto con anterioridad a la fecha que expone en el texto, y que concuerda con su $90^{\circ}$ cumpleaños. Tanto en esta publicación de $S U R$ como en la posterior de Poemas malagueños ya citada (p. 108), apareció con el título Nonagenario. El poema completo que he transcrito bajo el título Noventa apareció en Poesía, RIIP, ya citada, pp. 30-31.

19 El último acto conmemorativo del 90 cumpleaños del poeta se llevó a cabo el lunes 24 de enero de 1983 en el Salón de Actos de la Facultad de Filosofía y Letras de Málaga. 
Me es difícil convertir en tu fiesta

precisamente un día

que es como cualquier otro.

Desde hace muchos años

nuestra vida diaria se mantiene

y de modo fatal,

en amor compartido:

hondo enamoramiento.

Hoy el vivir, que es serio

y siempre apasionado

va deslizándose con propio impulso

de nuestro doble río.

¡Oh vida cotidiana! Sin disculpa ${ }^{20}$.

Este poema, dedicado a su esposa Irene en la fecha que se advierte en el encabezamiento, aborda un tema similar al presentado en la Segunda carta urgente (Final, p. 110), por lo que tal vez vaya en la segunda edición junto a éste.

\section{RONSARD. «LES AMOURS»}

Quand vous serez bien vieille, au soir, à la chandelle

Cuando seréis muy vieja, frente a luz de candela, sentada junto al fuego, hilando y conversando, diréis, y con asombro, ante mis versos-cantos, Ronsard me celebraba cuando yo era hermosa.

Entonces la sirvienta, oyendo tal noticia, y bajo su labor a medias soñolienta, al oír mis elogios había de despertarse vuestro nombre alabando en una inmortal loa.

Yo estaré bajo tierra, y fantasma sin huesos, a la sombra de mirtos lograré mi descanso. Junto a la lumbre os veo anciana acurrucada.

Sintiendo aún mi amor, lamentando el orgullo, vivid, hacedme caso, no esperéis a mañana, y desde hoy coged las rosas de la vida.

Cueuillez des aujourd'hui les roses de la vie. ${ }^{21}$

\section{Esta traducción de Ronsard debe incorporarse a la sección Otras}

Este poema fue publicado en su forma manuscrita en Ínsula, n. ${ }^{\circ} 435-436$, febreromarzo de 1983 , p. 2, número en homenaje al poeta.

Esta traducción de Ronsard fue editada por Ínsula en su número 435-436 ya citado, p. 7. Allí se hace constar que había sido publicado por Rafael León en edición facsímil de seis ejemplares, como número IV de la colección «Juan de Yepes», Málaga, 29 de septiembre de 1982. En Ínsula aparece también el soneto original de Ronsard y una variación de dos cuartetos sin rima a cargo de $\mathrm{M}^{\mathrm{a}}{ }^{\mathrm{V}} \mathrm{V}$. Atencia. 
variaciones, después de Poliziano, como le corresponde por orden cronológico, que es el utilizado por el poeta en toda la sección. Si bien el sentido del texto de Guillén es el mismo que el del poeta francés, existen un buen número de variantes que hacen el poema guilleniano, que ya he abordado en otro lugar.

\section{RUMORES}

El dulce murmurar de este nido, el mover de los árboles al viento.

GARCILASO, Égloga Segunda

Ese rumor tendrá también lo suyo: enigma con su hondura, su misterio, jamás de trascendencia yo no huyo: el orbe guarda siempre un fondo serio. ${ }^{22}$

En la última etapa de su vida, aunque deseaba seguir leyendo a autores poco leídos, en especial los presocráticos, J. Guillén volvió a leer a aquellos escritores con los que se había deleitado en su juventud, de ahí la aparición de este poema.

\section{EL JUEGO Y LA GUERRA}

¿Juega usted al ajedrez?

-Ignoro ese juego ilustre.

Pero mi vida y mis obras

se reducen a jugar.

Es el modo corriente de ser civilizados.

Las ciencias y las artes asi se desenvuelven.

Convergen los esfuerzos

hacia las creaciones del espíritu.

- ¿Y si el cuerpo se turba y no funciona?

-Entonces no se juega.

La falta de salud exige los cuidados

de especiales peritos.

¿Más, más vida? Más juego.

- ¿Esa es toda la Historia?

-Nunca, nunca jamás.

Habrá enemigos siempre que nos manden verter ríos sangrientos. ;Guerras, guerras!

Una de dos: jugamos o matamos.

¡Lejos el ajedrez! ${ }^{23}$

22 Este serventesio se publicó en Poesía, RIIP, ya citada, p. 32, y en Revista de Feria del Ayuntamiento de Fernán-Núñez, 1984, [s.p.]

23 Uno de los más largos de la última época de Guillén, este poema se publicó en Doce reflexiones al aguafuerte sobre Juan Carlos de Borbón y Doce apuntes literarios sobre el curioso juego del Ajedrez, Alfredo Melgar, Editor, M., 1983, [s.p.]. 
Siendo éste un poema compuesto exprofeso para la edición en que fue publicado, y sobre un tema muy concreto, predeterminado, asombra observar de qué modo da cabida a los asuntos más comunes de Final: la convivencia pacífica, la salud inspiradora, el ansia de vivir, la Historia, la guerra y el crimen.

\title{
MISTERIOSO
}

\begin{abstract}
Para el video misterioso vuelve el pasado en movimiento $\mathrm{y}$ el instante insignificante llega en seguida a conmovernos.

¿Y por qué? Porque significa. No cruzan su influjo y su tiempo, frente a nuestros ojos atónitos, sin arrastrarnos a lo inmenso, ese impulso que es esencial, contra mareas, contra vientos, jamás contacto con Nada, Nada irreal que es siempre un sueño, la gran verdad nos oculta: El vivir del amigo muerto. ¿Cómo?
\end{abstract}

\section{Salinas.}

Es él y todo el universo. ${ }^{24}$

Me emociono.

Como tantos otros, éste es un poema que surge de una anécdota determinada, una película proyectada ante el poeta por los hijos de su amigo, pero Guillén sabe aprovechar su propia emoción dándole un sentido universal al poema: el ansia de vivir, la vida y la muerte, el más allá vuelven a ser, junto con la Nada, que aborda en tantos momentos de Final, los temas recurrentes.

Por su estructura viene a engrosar el número de romances isométricos eneasílabos que contaba ya con otros tres ejemplos en la primera edición de la obra (pp. 99, 216 y 233). Creo que tiene cabida en el apartado III de Otras variaciones.

\author{
LA JOLLA (California) \\ 14-II-1975 \\ Con un solo impulso \\ eres pura gracia
}

24 Fue publicado en El Norte de Castilla, 7-2-1984, p. 36, y en Banda de Mar n. ${ }^{\circ} 7$ [s.p.], Málaga, 1984. En el primer caso lleva por título Misterio, tal vez por errata, y comienza por la preposición «Por». 
de palabra y niña,

Eugenia: vas hacia

la Eugenia mejor

ya desde este albor. ${ }^{25}$

Como puede observarse, el poeta prescindió de la letra mayúscula al iniciar cada verso para facilitar la lectura a su destinataria, una niña que cumplía 10 años.

\section{Poemas inéditos}

Escasos son los poemas aún inéditos destinados a la segunda edición de Final. Tengo la ocasión de presentarlos aquí como primicia:

\section{DESPUÉS, MUCHO DESPUÉS \\ Nuestra pasión fue trágico sainete BÉCQUER}

El amor reunió maravillas, riberas, iluminó caminos en fervores secretos, y cuando me estremece la final baraúnda que a todos fue manchando la propia dignidad, me dan lástima todos: confusos responsables de un amor corrompido, sucia luz a los ojos de los siempre conscientes, ya la moral perdida por entre los abusos y burlas de un sainete.

Soledad, ay, nostalgias con sus remordimientos.

No es demasiado frecuente el tema de la soledad en la poesía guilleniana ${ }^{26}$, y menos aún en Final, donde tal posibilidad se niega siempre $^{27}$. Su aparición aquí origina un notable contraste, contraste obser-

25 Este poema fue incluido en el artículo «Querida Eugenia», de M. ${ }^{a}$ V. Atencia, publicado en el homenaje que La Pluma en su $2 .^{a}$ época (n. ${ }^{\circ}$ ), dedicó al poeta en 1981, p. 94. Puede encontrarse también en J. G., Poemas malagueños, ya citado, p. 50 .

26 «Yo estoy en contacto con la realidad. Hay que estar en relación con lo otro, hay que salir de la soledad, del miedo. Mi tema es la compañía [...]. La soledad puede ser un punto de partida, pero la vida es compañía». Palabras de J. Guillén en entrevista de A. García Rayo, Cuadernos para el Diálogo, n. ${ }^{\circ} 205,2 .^{a}$ época, abril 1977, p. 7. Por su parte, B. Ciplijauskaité afirma: «El temperamento que se trasluce en la obra no es el de un solitario. Su sumo gozo es la realidad, y en la realidad el hombre nunca está solo. Deber de plenitud, Secretaría de Educación Pública, México, 1973 , p. 56.

27 Algunos ejemplos justifican mi afirmación: P. 102, v. 11: «Soledad. Soledad jamás 
vable en la misma disposición del poema, cuyo último verso aislado muy bien pudiera querer expresar el aislamiento del poeta frente a un mundo que ha perdido la noción del amor y la moral.

Ignoro la definitiva ubicación de este texto, que tal vez quepa también en el apartado III de Otras variaciones.

\section{TODOS O CASI TODOS JUNTOS}

En muchos medios comunicativos, periódicos, televisiones, se dan noticias de todo el planeta. Oriente y Occidente, Sur y Norte. La novedad del día puede venir de lejos, de salvajes. En equilibrios internacionales ¿qué fuerzas ya no influyen? ${ }^{28}$

No fue nunca ajeno J. Guillén a la realidad social y tampoco a los adelantos técnicos. El título y el contenido del poema parecen indicar una visión del hombre inter-dependiente del hombre, en un deseo de una Humanidad abierta y relacionada en la que todos dependemos de todos. Tal vez tenga cabida en algún apartado de Epigramas.

\section{GOLPE}

El Ejército al Poder, se lee en una pared.

Nada nuevo habrá que hacer.

La evolución detened.

Deseo de minoría.

¿Sí una Inquisición habría! ${ }^{29}$

Como esta sextilla forma conjunto con otros dos poemas ya señalados en nota 29 , y el tema parece corresponderse con un hecho muy concreto, omito todo comentario.

de veras». P. 110, v. 15: «¿Soledades? Jamás». P. 191, vv. 13-14: «A soledades no voy,/de soledades no vengo». P. 270, v. 7: «Pasen minutos. Soledad destruye».

28 Existe una variante a este poema:

V. 1: En los medios de comunicación.

V. 4: Oriente y Occidente, Norte y Sur.

V. 7: En el económico equilibrio.

V. 8: ¿Qué factores no influyen?

V. 9: Provinciano elemento ya no existe.

29 En el manuscrito original se indica que este poema irá en la página siguiente a Pesadilla y Lo peorcito. 


\title{
LA PEOR TRADICIÓN
}

La Historia nos suena al fin vulgar sainete - a la vez tragicomedia, y sus personajillos, con desplantes de payasos. Y la fuerza con armas quiere el poder, quisiera ser eterno. Abajo los peores,

los pésimos, los ínfimos. ${ }^{30}$

En este poema, cuyo título nos recuerda por oposición El mejor cuento de la tradición que ya he abordado, encuentro encomitancias con Después, mucho después, ya que en ambos textos se utiliza el término sainete con una visión peyorativa. No es tampoco ajeno en su temática a Golpe, por lo que acaso pueda ocupar un lugar cercano en la segunda edición de la obra.

\author{
EL POETA JOVEN \\ A Salvador López Becerra ${ }^{31}$ \\ Es joven, \\ y aspira a ser él mismo. \\ Por eso, por de pronto, \\ se inspira en el museo: \\ Arranque afortunado \\ para llegar a ser original. \\ No es así la loa de sí propio \\ un nuevo sentimiento \\ se despertaba al fin. \\ Casi un roce. $Y$ ya es la creación. \\ $Y$ sin ningún programa \\ se mueve «hacia la vida». \\ Algún pasado impulsa \\ también por vía nueva \\ deseo enamorado \\ de algún abencerraje; \\ escultura marmórea \\ no gracioso. Delicado y sereno,
}

30 Otra versión de este poema, en su último verso propone:

Abajo los peores, los pésimos, los mínimos.

31 Salvador López Becerra (Málaga, 1956), poeta y editor, publica unas hojas de poesía que llevan por título Torre de las palomas. En ellas dio a la luz editorial J. Guillén su Segunda carta urgente, así como Pesadilla.

Este joven poeta, director con D. García de Bégar Ediciones, editó a principios de enero de 1984 Niños, de J. Guillén. 
Isla ¿Mortal? Se busca su belleza.

Creaciones de joven.

Como en otras ocasiones, J. Guillén toma citas de textos de sus amigos para dedicarles un poema. Es lo que ha hecho con Alfonso Canales (p. 312), Vicente Aleixandre (pp. 304-306), y otros de Final. Tal vez por eso convendrá incluir este poema en la sección Otras variaciones.

\section{Consideraciones finales}

Es vano imaginar hasta dónde hubiera llegado la labor creadora y correctora de $\mathbf{J}$. Guillén si hubiera vivido un par de años más. Su esfuerzo corrector y creador queda, sin embargo, patente en los numerosos apuntes efectuados sobre la primera edición de la obra. Su constante reflexión de lo escrito lo llevó a trasladar textos de un lugar a otro del libro a fin de que pudieran encajar mejor dentro del conjunto. Es, en efecto, la misma técnica de Cántico, sólo que en aquella ocasión el poeta disfrutó de más de 40 años para introducir novedades.

Los poemas que acabamos de ver son, por otra parte, continuaciones de Final, y encajan perfectamente en cada una de las secciones del libro a las que estaban destinados. A veces, no obstante, cuando la voluntad del poeta no quedó manifiesta, puede elegirse más de una zona del libro para incluirlos, y de ahí la dificultad de preparar la segunda edición.

En cuanto a los temas abordados, es indudable que el poeta aprovecha los últimos instantes de su vida para volver a agradecer a sus amigos y a su esposa las atenciones que ha recibido de ellos, pero también quiere poner los puntos sobre las íes en determinadas cuestiones que le parecen capitales, esto es, el avance de la tecnología y el retroceso de la moral.

Los acontecimientos sociales y políticos (intento de golpe de Estado, crímenes diversos, etc.) así como su propia vida personal (aniversarios) son los temas más repetidos, pero tampoco olvida, como se ha visto, las traducciones y el comentario de textos ajenos.

Puede admitirse también que permaneció fiel al compromiso histórico y social adquirido desde Clamor y presente ya en algunos poemas de Cántico, y que su tono lírico no decayó en ningún momento. 
$Y$ en cuanto a los moldes utilizados en los últimos poemas, observamos los mismos de la primera edición, $\mathrm{y}$, aunque predominen los versos libres (endecasílabos, heptasílabos, eneasílabos y octosílabos), no se olvida de algunas de las composiciones poéticas con las que ha alcanzado justa fama, como el romance y las estrofas de cuatro versos de índole epigramático.

En resumidas cuentas, el último legado de J. Guillén participa, sin menoscabo aparente, de las cualidades líricas, temáticas y formales de sus mejores obras. Guillén fue Guillén hasta el último de sus poemas. 